\title{
Early Pregnancy Vitamin D Binding Protein Is Independently Associated with the Development of Gestational Diabetes: A Retrospective Cohort Study
}

\author{
Melinda Fernando ${ }^{1}$, Stacey J. Ellery ${ }^{2}{ }^{\circledR}$, Deborah de Guingand ${ }^{2}{ }^{\circledR}$, Clara Marquina $^{1}{ }^{1}$, \\ Siew Lim ${ }^{1}$, Cheryce L. Harrison ${ }^{1}$, Helena J. Teede ${ }^{1}\left(\mathbb{D}\right.$, Negar Naderpoor $^{1,+} \mathbb{D}$ and \\ Aya Mousa ${ }^{1, *,+}$ (iD \\ 1 Monash Centre for Health Research and Implementation (MCHRI) and Centre of Cardiovascular Research \\ and Education in Therapeutics (CCRET), School of Public Health and Preventive Medicine, \\ Monash University, 43-51 Kanooka, Grove, VIC 3168, Australia; melinda.fernando@monash.edu (M.F.); \\ clara.marquina@monash.edu (C.M.); siew.lim1@monash.edu (S.L.); cheryce.harrison@monash.edu (C.L.H.); \\ helena.teede@monash.edu (H.J.T.); negar.naderpoor@monash.edu (N.N.) \\ 2 The Ritchie Centre, Hudson Institute of Medical Research and Department of Obstetrics and Gynaecology, \\ Monash University, 43-51 Kanooka, Grove, VIC 3168, Australia; stacey.ellery@hudson.org.au (S.J.E.); \\ deborah.deguingand@hudson.org.au (D.d.G.) \\ * Correspondence: aya.mousa@monash.edu \\ + Joint senior authors.
}

Received: 18 June 2020; Accepted: 8 July 2020; Published: 10 July 2020

check for updates

\begin{abstract}
Background: Vitamin D-binding protein (VDBP) has been implicated in several adverse pregnancy outcomes either directly or indirectly via influencing the concentrations of biologically active vitamin D metabolites. However, human studies exploring these metabolites in pregnancy remain sparse. Here, we examine whether VDBP and total, free, and bioavailable 25-hydroxyvitamin $\mathrm{D}(25(\mathrm{OH}) \mathrm{D})$ metabolites in early pregnancy are associated with subsequent adverse pregnancy outcomes. Methods: We conducted a retrospective analysis of 304 pregnant women in early pregnancy ( $<20$ weeks gestation). The demographic characteristics, anthropometric data, and total $25(\mathrm{OH}) \mathrm{D}$ were measured and plasma or serum samples were collected and bio-banked. Using these samples, we measured VDBP (polyclonal ELISA) and albumin (automated colorimetry), and calculated free and bioavailable 25(OH)D using validated formulae. Pregnancy outcomes were derived from scanned medical records. Regression models were used to analyse the relationships between vitamin D metabolites in early pregnancy and subsequent pregnancy outcomes (gestational diabetes mellitus (GDM), pre-eclampsia, preterm birth), with adjustment for predetermined clinically relevant maternal factors including age, body mass index (BMI), and ethnicity. Results: Lower VDBP concentrations were associated with higher glucose levels and a greater likelihood of developing GDM at 26-28 weeks gestation (odds ratio [OR] $(95 \% \mathrm{CI})=0.98(0.97,0.99), p=0.015)$. This finding remained significant after adjustment for maternal covariates including age, BMI, and ethnicity $(\beta=-0.003, p=0.03)$. Lower total, free and bioavailable 25(OH)D, but not VDBP, were associated with a shorter length of gestation, but only the relationship with total $25(\mathrm{OH}) \mathrm{D}$ remained significant after adjustment for the above maternal covariates $(\beta=0.02, p=0.006)$. Conclusions: This is the first study to examine VDBP, and total, free and bioavailable $25(\mathrm{OH}) \mathrm{D}$ in relation to pregnancy outcomes in a well characterised multi-ethnic cohort of pregnant women. Our findings show that VDBP and total 25(OH)D are associated with GDM and length of gestation, respectively; however, further investigations using large-scale prospective studies are needed to confirm our findings.
\end{abstract}

Keywords: vitamin D binding protein; free vitamin D; bioavailable vitamin D; pregnancy; gestational diabetes mellitus; glucose tolerance 


\section{Introduction}

Vitamin D has a well established role in calcium homeostasis and bone mineralisation, and has been shown to contribute to other biological processes including inflammation [1], immunoregulation and cardiometabolic health [2,3]. During pregnancy, there is an increased requirement for vitamin D to meet heightened physiological and metabolic demands in the mother and to support fetal skeletal bone mineralisation [4]. Vitamin D deficiency in pregnancy has been linked with several adverse pregnancy outcomes including pre-eclampsia, gestational diabetes mellitus (GDM) and preterm birth [2]. In particular, GDM is a common pregnancy complication closely linked to maternal obesity and its incidence has been linked to several lifestyle factors including nutritional inadequacies such as vitamin D deficiency [5]. However, published results are inconsistent and current classifications for vitamin D deficiency or optimal concentrations during pregnancy remain contentious [2,3].

Recent evidence suggests that vitamin D binding protein (VDBP) is critical for maintaining vitamin D homeostasis in pregnancy [6]. VDBP is the main carrier of vitamin D and its concentrations increase during pregnancy (mainly in response to rising oestrogen), altering the concentrations of, and the relationships between, total and free 25-hydroxyvitamin $\mathrm{D}(25(\mathrm{OH}) \mathrm{D})$ [7]. Currently, total 25(OH)D concentrations are used to determine vitamin $\mathrm{D}$ status and to define deficiency [2]. Free or unbound $25(\mathrm{OH}) \mathrm{D}$ makes up less than $1 \%$ of total serum $25(\mathrm{OH}) \mathrm{D}$, while bioavailable $25(\mathrm{OH}) \mathrm{D}$, which includes a combination of free $25(\mathrm{OH}) \mathrm{D}$ and albumin-bound $25(\mathrm{OH}) \mathrm{D}$ (with much lower binding affinity) makes up approximately $10-15 \%$ of total $25(\mathrm{OH}) \mathrm{D}$ [6]. The 'free hormone hypothesis' posits that only free steroid hormones are physiologically active since their lipophilic ability enables their passive diffusion across cell membranes [6]. This demonstrates the potential importance of VDBP since it directly regulates the circulating amounts of the biologically active free vitamin D [6], as well as preventing the urinary loss of vitamin D [8]. However, existing studies exploring vitamin D in pregnancy have focused primarily on total $25(\mathrm{OH}) \mathrm{D}$ as a single measure of vitamin $\mathrm{D}$ status, which may be inadequate for representing functional vitamin D status.

Independent of its role in vitamin D transport and regulation, VDBP has been shown to directly influence several biological processes that are often exacerbated in the pregnant state, including immunoregulation, inflammation, glucose metabolism, and the regulation of blood pressure [9]. Studies report that VDBP is enhanced during pro-inflammatory states and that it maintains an environment of tolerance to paternal and foetal tissue and their accompanying alloantigens [6]. Despite the increased recognition of the possible multifunctional role of VDBP in promoting a healthy pregnancy, human studies examining the relationships between VDBP and pregnancy outcomes remain sparse. These studies have been reviewed by our group [10] and others [6], highlighting key limitations in the evidence including small sample sizes, minimal ethnic diversity, and the lack of adjustment for potential confounding variables (obesity, age, ethnicity, lifestyle factors), all of which can affect both VDBP levels and pregnancy outcomes [11-13]. Ethnicity in particular is associated with genetic polymorphisms which influence VDBP concentrations, binding capacity, and function [14-16]. Previous studies are also limited by the use of monoclonal immunoassays to measure VDBP, which have a different selective affinity for VDBP genotypes and are considered less accurate than polyclonal assays for measuring VDBP and subsequently calculating free 25(OH)D [17]. Studies addressing these knowledge gaps may be useful to enhance our understanding of the complex vitamin D network and to potentially identify biomarkers to facilitate risk prediction and prevention of adverse pregnancy outcomes.

Therefore, we aimed to examine whether maternal concentrations of VDBP, and total, free and bioavailable $25(\mathrm{OH}) \mathrm{D}$ metabolites in early pregnancy were associated with subsequent pregnancy outcomes in a well characterised multi-ethnic cohort of pregnant women. We tested the hypothesis that VDBP concentrations in early pregnancy will be correlated with adverse pregnancy outcomes either directly and/or indirectly via influencing free and bioavailable 25(OH)D concentrations. 


\section{Experimental Section}

\subsection{Study Design and Population}

This study is a longitudinal retrospective cohort study of 304 pregnant women. Datasets and pre-collected bio-banked samples from two separate populations were combined and analysed in this study and their respective inclusion criteria are described in Table 1. The first population was derived from the healthy lifestyle in pregnancy (HLP) study cohort [18], which comprised 228 women initially recruited from Monash Health (three large tertiary hospitals in Melbourne, Australia). These women were recruited during early pregnancy ( $<15$ weeks gestation) for a randomised controlled trial (RCT) which aimed to prevent excess gestational weight gain in women classified as high risk for the development of GDM, based on a validated risk prediction tool [19]. Of these women, 103 were in the HLP control group (receiving standard care) and the data and samples for these 103 control group women were sought for the present study.

Table 1. Criteria for the inclusion and exclusion of participants in the HLP and CPO cohorts.

\begin{tabular}{|c|c|c|c|}
\hline \multicolumn{2}{|c|}{ Inclusion Criteria } & \multicolumn{2}{|c|}{ Exclusion Criteria } \\
\hline HLP Cohort & CPO Cohort & HLP Cohort & CPO Cohort \\
\hline Age $\geq 18$ years & Age $18 \leq 40$ years & Age $<18$ years & Age $<18$ or $>40$ years \\
\hline \multicolumn{2}{|c|}{ Singleton pregnancy } & \multicolumn{2}{|c|}{ Multiple pregnancy } \\
\hline $\begin{array}{l}\text { High risk of GDM } \\
\text { (scoring } \geq 3 \text { on risk } \\
\text { prediction tool [19]) }\end{array}$ & $\begin{array}{l}\text { Low-risk pregnancy } \\
\text { (based on } \\
\text { medical/obstetric } \\
\text { history) }\end{array}$ & $\begin{array}{l}\text { Known pre-existing } \\
\text { diabetes diagnosis } \\
\text { (any diabetes) }\end{array}$ & $\begin{array}{l}\text { High-risk pregnancy } \\
\text { (requiring care in } \\
\text { high-risk clinic) }\end{array}$ \\
\hline $\begin{array}{c}\leq 15 \text { weeks gestation at } \\
\text { recruitment }\end{array}$ & $\begin{array}{l}\text { 10-20 weeks gestation } \\
\text { ( } \pm 1 \text { week) at recruitment }\end{array}$ & $\begin{array}{c}\text { Other chronic medical } \\
\text { conditions precluding } \\
\text { participation }\end{array}$ & $\begin{array}{l}\text { Models of care outside } \\
\text { tertiary public hospital } \\
\text { care (e.g., private, shared, } \\
\text { or GP/midwife care) }\end{array}$ \\
\hline \multicolumn{2}{|c|}{ English speaking } & \multicolumn{2}{|c|}{ Non-English Speaking } \\
\hline $\begin{array}{l}\text { Overweight/obese: BMI } \\
\geq 25 \mathrm{~kg} / \mathrm{m}^{2} \text { (or } \geq 23 \mathrm{~kg} / \mathrm{m}^{2} \\
\text { in high-risk ethnicities) } \\
\text { or } \geq 30 \mathrm{~kg} / \mathrm{m}^{2}\end{array}$ & $\begin{array}{l}\text { Attending Monash } \\
\text { Health for labour }\end{array}$ & $\begin{array}{l}\text { Morbidly obese } \\
\left(\mathrm{BMI} \geq 45 \mathrm{~kg} / \mathrm{m}^{2}\right)\end{array}$ & $\begin{array}{l}\text { Use of creatine } \\
\text { supplements in } \\
\text { pregnancy }\end{array}$ \\
\hline
\end{tabular}

Abbreviations: HLP, healthy lifestyle in pregnancy; CPO, creatine and pregnancy outcomes; GDM, gestational diabetes mellitus; BMI, body mass index; GP, general practice.

The second population, the creatine and pregnancy outcomes (CPO) cohort, were a low risk pregnancy group (participants with significant medical or obstetric history were excluded; Table 1). This cohort was recruited in early pregnancy ( $<20$ weeks gestation), also from Monash Health, for a prospective observational study aimed at characterising creatine homeostasis in low-risk pregnancies [20]. The CPO low-risk pregnancy cohort recruited 282 pregnant women, of which 18 subsequently withdrew or were excluded, and 264 remained involved until the study conclusion.

Of the 103 women in the HLP control cohort and the 264 in the CPO cohort, our current analysis utilised data and bio-banked samples from 91 and 213 women, respectively (total $n=304$ ). The remaining women could not be included due to missing data, insufficient samples (for the laboratory analysis of VDBP and albumin) and/or unreliable assay measures.

\subsection{Ethics}

All participants provided informed written consent prior to participation and all the data were de-identified for use in this study. The HLP high-risk pregnancy cohort study was approved by the Monash Health Research Advisory and Ethics Committee (07216C) initially in 2008, and in 2019 for the current retrospective study (19674). For the low-risk CPO pregnancy cohort, ethics approval was obtained in 2015 from Monash Health (14140B) and Monash University (7785), and in 2019 for the current retrospective study (HREC/51952/MonH-2019-169657(v2)). 


\subsection{Sample and Data Collection}

The data were collected at several stages in the two cohorts. The timepoints, data collected, and methods are summarised in Table 2. The maternal outcomes were determined by routine clinical assessments and derived for the purpose of this study from the Birthing Outcomes System (BOS) database which uses a standardized method of reporting perinatal data in Victoria, Australia [19]. Oral glucose tolerance test (OGTT) values at 26-28 weeks were used to diagnose GDM based on the 2014 Australasian Diabetes in Pregnancy Society criteria [21]. Pre-eclampsia and preterm birth $(<37$ weeks gestation) were diagnosed based on the Royal Australia New Zealand College of Obstetricians and Gynaecologists guidelines [22].

Table 2. Data collected at different gestational timepoints in the HLP and CPO pregnancy cohorts.

\begin{tabular}{|c|c|c|}
\hline Timepoint (Gestation) & Data Collected in Both Cohorts & Methods \\
\hline \multirow[t]{3}{*}{$<20$ weeks } & $\begin{array}{l}\text { Demographic characteristics: age, } \\
\text { ethnicity, parity, smoking status, } \\
\text { medical history }\end{array}$ & Demographic questionnaires \\
\hline & BMI, weight, height & $\begin{array}{l}\text { Weight }(\mathrm{kg}) / \text { height }(\mathrm{m})^{2} \text { measured directly } \\
\text { or calculated from SMR }\end{array}$ \\
\hline & $\begin{array}{l}\text { Fasting plasma glucose; } \\
\text { serum/plasma total } 25(\mathrm{OH}) \mathrm{D}, \\
\text { albumin, VDBP }\end{array}$ & $\begin{array}{c}\text { Fasting venous blood samples and } \\
\text { commercial assays for plasma glucose and } \\
\text { total 25(OH)D; albumin and VDBP } \\
\text { measured in bio-banked samples by } \\
\text { Monash Pathology and Hudson laboratory } \\
\text { (detailed below) }\end{array}$ \\
\hline 26-28 weeks & $\begin{array}{l}\text { GDM diagnosis, fasting glucose, } 1 \\
\text { h glucose post-OGTT, and } 2 \mathrm{~h} \\
\text { glucose post-OGTT. }\end{array}$ & $\begin{array}{l}\text { Data retrieved from routine OGTTs } \\
\text { recorded on BOS or SMR. GDM diagnosed } \\
\text { based on } 2014 \text { ADIPS criteria: FBG } 5.1 \text { or } \\
\text { over and/or } 2 \text { h glucose } 8.5 \text { or over }(\mathrm{mmol} / \mathrm{L})\end{array}$ \\
\hline $\begin{array}{l}\text { During pregnancy/ } \\
\text { at birth }\end{array}$ & $\begin{array}{l}\text { Maternal outcomes and } \\
\text { complications (including } \\
\text { pre-eclampsia, pregnancy-induced } \\
\text { hypertension, preterm birth) }\end{array}$ & Data retrieved from BOS and SMR \\
\hline
\end{tabular}

Abbreviations: 25(OH)D, 25-hydroxyvitamin D; ADIPS, Australasian Diabetes in Pregnancy Society; BMI, body mass index; BOS, Birthing Outcomes System; FBG, fasting blood glucose; GDM, gestational diabetes; HLP, healthy lifestyle in pregnancy; CPO, creatine and pregnancy outcomes; OGTT, oral glucose tolerance test; SMR, scanned medical records; VDBP, vitamin D binding protein.

\subsection{Biochemical Analyses}

\subsubsection{Archived Data (Serum Glucose, Total 25(OH)D)}

As shown in Table 2 above, fasting glucose was measured in fasting serum samples collected in early pregnancy ( $<20$ weeks), while the OGTT glucose levels (fasting, $1 \mathrm{~h}$ and $2 \mathrm{~h}$ ) were measured in serum samples collected at 26-28 weeks gestation. These glucose measures were collected in accordance with routine care at Monash Health and were analysed by Melbourne Pathology and Monash Health Pathology using commercial enzyme-linked immunosorbent assays (ELISA) with the relevant quality control standards.

Total 25(OH)D concentrations were measured in early pregnancy serum samples ( $<20$ weeks) by Monash Health Pathology using direct competitive chemiluminescent immunoassays on a LIAISON analyser (DiaSorin Inc., Stillwater, MN, USA), with inter- and intra-assay coefficients of variation (CVs) of $<10 \%$ and $<4 \%$, respectively.

\subsubsection{VDBP Analysis}

For the purpose of this study, we measured VDBP in samples which were stored at $-80^{\circ} \mathrm{C}$ in departmental bio-banks. The VDBP analyses were conducted using polyclonal competitive ELISA assays (Abcam ab108853), according to the manufacturer's instructions. The samples were run in duplicate at random across nine plates, with a calibrator sample used to determine the inter-assay variability and normalise the measures across the plates. Before correction, the intra- and inter-assay 
CVs were $<12 \%$ and $<22 \%$, respectively. We proceeded to calculate adjustment factors from the calibrator sample and conducted the analysis using the adjusted results, where appropriate.

\subsubsection{Albumin Analysis}

Albumin was measured in order to calculate free and bioavailable $25(\mathrm{OH}) \mathrm{D}$ values using the formula by Bikle et al. [23]. The samples were analysed by Monash Health Pathology using an automated colorimetric method carried out on a Beckman Coulter AU5812 System.

\subsection{Calculation of Free and Bioavailable 25(OH)D}

Using the formula by Bikle et al. [23], free 25(OH)D was calculated based on the affinity binding constants for $25(\mathrm{OH}) \mathrm{D}$ with albumin and VDBP $\left(6 \times 10^{5} \mathrm{M}^{-1}\right.$ and $7 \times 10^{8} \mathrm{M}^{-1}$, respectively $)$ as determined using centrifugal ultrafiltration dialysis. The calculations used for free and bioavailable vitamin $\mathrm{D}$ and the relevant unit conversions are summarised below:

$$
\begin{gathered}
V D_{\text {free }}=\frac{V D_{\text {total }}}{\left(1+\left(6 \times 10^{5}\right) \times A l b\right)+\left(\left(7 \times 10^{8}\right) \times V D B P\right)} \\
V D_{\text {bio }}=\left(1+\left(6 \times 10^{5}\right) \times A l b\right) \times V D_{\text {free }}
\end{gathered}
$$

where:

$V D_{\text {free }}=$ serum free $25(\mathrm{OH}) \mathrm{D}$ concentrations in $\mathrm{mol} / \mathrm{L}$;

$V D_{\text {total }}=$ serum total $25(\mathrm{OH}) \mathrm{D}$ concentration in $\mathrm{mol} / \mathrm{L}$;

$V D_{\text {bio }}=$ serum bioavailable $25(\mathrm{OH}) \mathrm{D}$ concentration in $\mathrm{mol} / \mathrm{L}$;

$A l b=$ serum albumin concentration in $\mathrm{mol} / \mathrm{L}$ (albumin was measured in $\mathrm{g} / \mathrm{L}$ and converted to $\mathrm{mol} / \mathrm{L}$ using: g/L $\div 66430$ );

$V D B P=$ serum vitamin $\mathrm{D}$ binding protein concentration in $\mathrm{mol} / \mathrm{L}(\mathrm{VDBP}$ was measured in $\mathrm{ug} / \mathrm{mL}$ and converted to $\mathrm{mol} / \mathrm{L}$ using: $\mu \mathrm{g} / \mathrm{mL} \div 5.8 \times 10^{7}$ ).

Free $25(\mathrm{OH}) \mathrm{D}$ is reported in $\mathrm{pg} / \mathrm{mL}$ and was converted from $\mathrm{mol} / \mathrm{L}$ to $\mathrm{pg} / \mathrm{mL}$ using: $\mathrm{mol} / \mathrm{L} \times$ $0.4166 \times 10^{12}$. Total and bioavailable $25(\mathrm{OH}) \mathrm{D}$ are reported in $\mathrm{nmol} / \mathrm{L}$ and were converted from $\mathrm{mol} / \mathrm{L}$ to $\mathrm{nmol} / \mathrm{L}$ using: $\mathrm{mol} / \mathrm{L} \times 10^{9}$.

\subsection{Statistical Analyses}

The participant demographics, clinical and biochemical parameters including vitamin D metabolites are presented as mean \pm standard deviation (SD) or frequencies (\%). Normality was determined using Shapiro-Wilk tests and by visual inspection of histograms. Non-normally distributed variables including total, free, and bioavailable $25(\mathrm{OH}) \mathrm{D}$ metabolites were logarithmically transformed to the base 10 to meet the assumptions of parametric statistical tests prior to data analysis. Univariable associations between the continuous vitamin D metabolite concentrations and continuous or categorical demographic or biochemical parameters were analysed using Pearson's correlations or chi-square tests. Univariable associations between vitamin D metabolites and continuous (e.g., length of gestation) or categorical pregnancy outcomes (e.g., binary 'with GDM' or 'without GDM') were analysed using general linear or simple logistic regression, respectively. Differences in the mean concentrations of the vitamin D metabolites between binary outcome groups (e.g., women with or without GDM) were explored using independent Student's $t$-tests.

Multiple linear and logistic regression models were used to adjust for predetermined maternal characteristics considered to be clinically relevant to the outcomes, including maternal age, body mass index (BMI), and ethnicity. Exploratory analyses of additional covariates such as smoking status, parity, or previous history of GDM were included as appropriate. The statistical analyses were performed using Stata V.15.0 (StataCorp, College Station, TX, USA) and a two-tailed $p<0.05$ was considered statistically significant. 


\section{Results}

\subsection{Sample Characteristics}

Three hundred and four pregnant women were included in this study and the sample characteristics are presented in Table 3. There were no differences between the two cohorts of women (HLP and CPO) in any demographic or anthropometric characteristics at early pregnancy ( $<20$ weeks gestation) including age, BMI, parity, and ethnicity (all $p>0.05$ ). The mean age of the participants was $31.4 \pm 4.2$ years (mean \pm SD) and $46 \%$ were primiparous. The sample was ethnically diverse, with approximately $43 \%$ being of non-Caucasian background (Table 3). Approximately $28.3 \%$ of participants were classified as overweight $\left(\mathrm{BMI} \geq 25 \mathrm{~kg} / \mathrm{m}^{2}\right)$ and $25.6 \%$ as obese $\left(\mathrm{BMI} \geq 30 \mathrm{~kg} / \mathrm{m}^{2}\right)$.

Table 3. The sample demographic, anthropometric, and biochemical characteristics and maternal pregnancy outcomes.

\begin{tabular}{|c|c|}
\hline Variable & Mean \pm SD or $n(\%)$ \\
\hline Maternal age (years) & $31.4 \pm 4.2$ \\
\hline \multicolumn{2}{|l|}{ Parity } \\
\hline Primiparous & $133(46.0)$ \\
\hline 2 & $106(36.7)$ \\
\hline 3 & $39(13.5)$ \\
\hline 4 & $11(3.8)$ \\
\hline \multicolumn{2}{|l|}{ Ethnicity } \\
\hline Caucasian & $174(57.4)$ \\
\hline South East and North East Asian & $37(12.2)$ \\
\hline Southern and Central Asian & $69(22.8)$ \\
\hline Other ${ }^{\text {a }}$ & $23(7.6)$ \\
\hline Past history of GDM & $13(4.3)$ \\
\hline BMI $\left(\mathrm{kg} / \mathrm{m}^{2}\right)$ & $26.8 \pm 5.9$ \\
\hline Gestational weight gain (kg, at 28 weeks) & $7.4 \pm 3.6$ \\
\hline \multicolumn{2}{|l|}{ Vitamin D metabolites } \\
\hline Total 25(OH)D, nmol/L (ng/mL) & $54.8 \pm 20.2(22.0 \pm 8.1)$ \\
\hline Free $25(\mathrm{OH}) \mathrm{D}(\mathrm{pg} / \mathrm{mL})$ & $5.6 \pm 4.7$ \\
\hline Bioavailable 25(OH)D (nmol/L) & $4.4 \pm 3.1$ \\
\hline $\operatorname{VDBP}(\mu \mathrm{g} / \mathrm{mL})$ & $364.7 \pm 126.1$ \\
\hline Albumin $(g / L)$ & $36.9 \pm 4.1$ \\
\hline \multicolumn{2}{|l|}{ Glycaemic measures } \\
\hline FBG at baseline $(<20$ weeks $)(\mathrm{mmol} / \mathrm{L})$ & $4.6 \pm 0.6$ \\
\hline FBG OGTT (26-28 weeks) (mmol/L) & $4.5 \pm 0.5$ \\
\hline 1 h OGTT (26-28 weeks) (mmol/L) & $7.6 \pm 1.9$ \\
\hline 2 h OGTT (26-28 weeks) (mmol/L) & $6.3 \pm 1.5$ \\
\hline \multicolumn{2}{|l|}{ Pregnancy outcome } \\
\hline Gestational diabetes mellitus & $55(19.4)$ \\
\hline Pre-eclampsia & $10(3.4)$ \\
\hline Placental abnormality & $102(48.1)$ \\
\hline Gestation at delivery (weeks) & $39.1 \pm 2.0$ \\
\hline Preterm birth & $16(5.4)$ \\
\hline Premature rupture of membranes & $42(20.4)$ \\
\hline Caesarean section & 75 (25.5) \\
\hline
\end{tabular}

Data reported as the mean \pm standard deviation or frequency $n(\%) ;{ }^{a}$ Other represents African, Middle-Eastern, European, South American and Polynesian. Abbreviations: GDM, gestational diabetes mellitus; T2DM, type 2 diabetes mellitus; BMI, body mass index; 25(OH)D, 25 hydroxyvitamin D; VDBP, vitamin D binding protein; FBG, fasting blood glucose; OGTT, oral glucose tolerance test.

At early pregnancy, the mean level of serum total $25(\mathrm{OH}) \mathrm{D}$ was $54.8 \pm 20.2 \mathrm{nmol} / \mathrm{L}$ $(22.0 \pm 8.1 \mathrm{ng} / \mathrm{mL})$. Only $14.5 \%$ of the sample had sufficient levels of vitamin D (total $25(\mathrm{OH}) \mathrm{D}$ $\geq 75 \mathrm{nmol} / \mathrm{L}$ or $\geq 30 \mathrm{ng} / \mathrm{mL}$ ) according to the US Endocrine Society guidelines [24], with $46.8 \%$ having insufficient levels (50-74.9 nmol/L or $20-29.9 \mathrm{ng} / \mathrm{mL}), 30.3 \%$ having deficient levels $(25-49.9 \mathrm{nmol} / \mathrm{L}$ or 
$10-19.9 \mathrm{ng} / \mathrm{mL}$ ), and $8.4 \%$ deemed severely deficient $(<25 \mathrm{nmol} / \mathrm{L}$ or $<10 \mathrm{ng} / \mathrm{mL}$ ). There was a total of 55 $(19.4 \%)$ cases of GDM, 10 cases (3.4\%) of pre-eclampsia, and 16 cases $(5.4 \%)$ of preterm birth (Table 3$)$.

\subsection{Univariable Analyses of Vitamin D Metabolites and Demographic and Anthropometric Variables}

The correlations between VDBP and total, free, and bioavailable 25(OH)D metabolites with demographic and anthropometric parameters are presented in Table 4. Higher maternal age was correlated with lower VDBP and higher free and bioavailable 25(OH)D concentrations (Table 4). A higher BMI correlated with lower VDBP and total 25(OH)D but was not associated with free or bioavailable $25(\mathrm{OH}) \mathrm{D}$ (Table 4). There were no associations between vitamin D metabolites and any other demographic characteristics (all $p>0.05$ ).

Table 4. Pearson correlations between vitamin D metabolites and maternal characteristics and glycaemic measures.

\begin{tabular}{|c|c|c|c|c|c|c|c|c|}
\hline \multirow[t]{2}{*}{ Variable } & \multicolumn{2}{|c|}{ VDBP } & \multicolumn{2}{|c|}{$\begin{array}{c}\text { Total } \\
\text { 25(OH)D * }\end{array}$} & \multicolumn{2}{|c|}{$\begin{array}{c}\text { Free } \\
25(\mathrm{OH}) \mathrm{D} *\end{array}$} & \multicolumn{2}{|c|}{$\begin{array}{c}\text { Bioavailable } \\
25(\mathrm{OH}) \mathrm{D}^{*}\end{array}$} \\
\hline & $r$ & $p$ & $r$ & $p$ & $r$ & $p$ & $r$ & $p$ \\
\hline \multicolumn{9}{|c|}{ Maternal characteristics } \\
\hline Age (years) & -0.24 & $<0.01$ & 0.11 & 0.07 & 0.22 & $<0.01$ & 0.24 & $<0.01$ \\
\hline BMI $\left(\mathrm{kg} / \mathrm{m}^{2}\right)$ & -0.12 & 0.047 & -0.26 & $<0.001$ & -0.11 & 0.08 & -0.09 & 0.1 \\
\hline \multicolumn{9}{|c|}{ Glycaemic measures } \\
\hline FBG (<20 weeks; mmol/L) & -0.02 & 0.7 & -0.06 & 0.3 & -0.003 & 0.9 & -0.02 & 0.7 \\
\hline FBG OGTT (26-28 wks; mmol/L) & -0.11 & 0.08 & -0.20 & $<0.001$ & -0.07 & 0.3 & -0.05 & 0.4 \\
\hline 1 h OGTT (26-28 weeks; mmol/L) & -0.17 & 0.007 & -0.20 & 0.001 & -0.02 & 0.8 & -0.02 & 0.8 \\
\hline 2 h OGTT (26-28 weeks; mmol/L) & -0.18 & 0.003 & -0.16 & 0.008 & 0.008 & 0.9 & 0.001 & 0.9 \\
\hline
\end{tabular}

All the data were assessed using Pearson correlations and are reported as the correlation coefficients $(r)$ with the corresponding $p$-values $(p)$. * Skewed variables were logarithmically transformed to the base 10 prior to analysis. Abbreviations: BMI, body mass index; FBG, fasting blood glucose; OGTT, oral glucose tolerance test; VDBP, vitamin D binding protein. Bold: denotes statistical significance at $p<0.05$.

In examining correlations between the vitamin D metabolites, VDBP was inversely associated with free and bioavailable 25(OH)D (both $r=-0.6, p<0.001$ ), but there was no association between VDBP and total $25(\mathrm{OH}) \mathrm{D}(p=0.8)$. Total $25(\mathrm{OH}) \mathrm{D}$ concentration was positively associated with free and bioavailable 25(OH)D (both $r=0.7, p<0.001$ ) and there was a positive correlation between the free and bioavailable 25(OH)D metabolites $(r=0.9, p<0.001)$.

\subsection{Univariable and Multivariable Analyses of Vitamin D Metabolites and Biochemical Variables}

Associations between vitamin D metabolites and glucose measures are presented in Table 4 and Figures 1 and 2. Higher VDBP concentrations in early pregnancy were associated with lower $1 \mathrm{~h}$ and $2 \mathrm{~h}$ glucose post-OGTT at 26-28 weeks (both $p<0.01$ ) but not with fasting glucose at OGTT $(p=0.08$, Table 4 and Figure 1). Similarly, higher total $25(\mathrm{OH}) \mathrm{D}$ concentrations in early pregnancy were associated with lower fasting glucose, as well as lower $1 \mathrm{~h}$ and $2 \mathrm{~h}$ glucose during OGTT at 26-28 weeks gestation (Table 4 and Figure 2). Free and bioavailable metabolites were not associated with any glucose measures (Table 4).

After adjusting for maternal covariates including age, BMI and ethnicity, VDBP remained associated with $1 \mathrm{~h}(\beta=-1.7, p=0.01)$ and $2 \mathrm{~h}$ glucose $(\beta=1.4, p=0.004)$, but not with fasting glucose $(p=0.2)$. A higher total $25(\mathrm{OH}) \mathrm{D}$ remained associated with fasting glucose $(\beta=-0.5, p=0.008)$ but was no longer associated with $1 \mathrm{~h}$ or $2 \mathrm{~h}$ glucose post-OGTT, although the results were borderline non-significant ( $p=0.06$ and $p=0.07$, respectively). There were no significant associations between the free or bioavailable $25(\mathrm{OH}) \mathrm{D}$ metabolites with the glucose measures in any of the multivariable models (all $p>0.1$ ). 

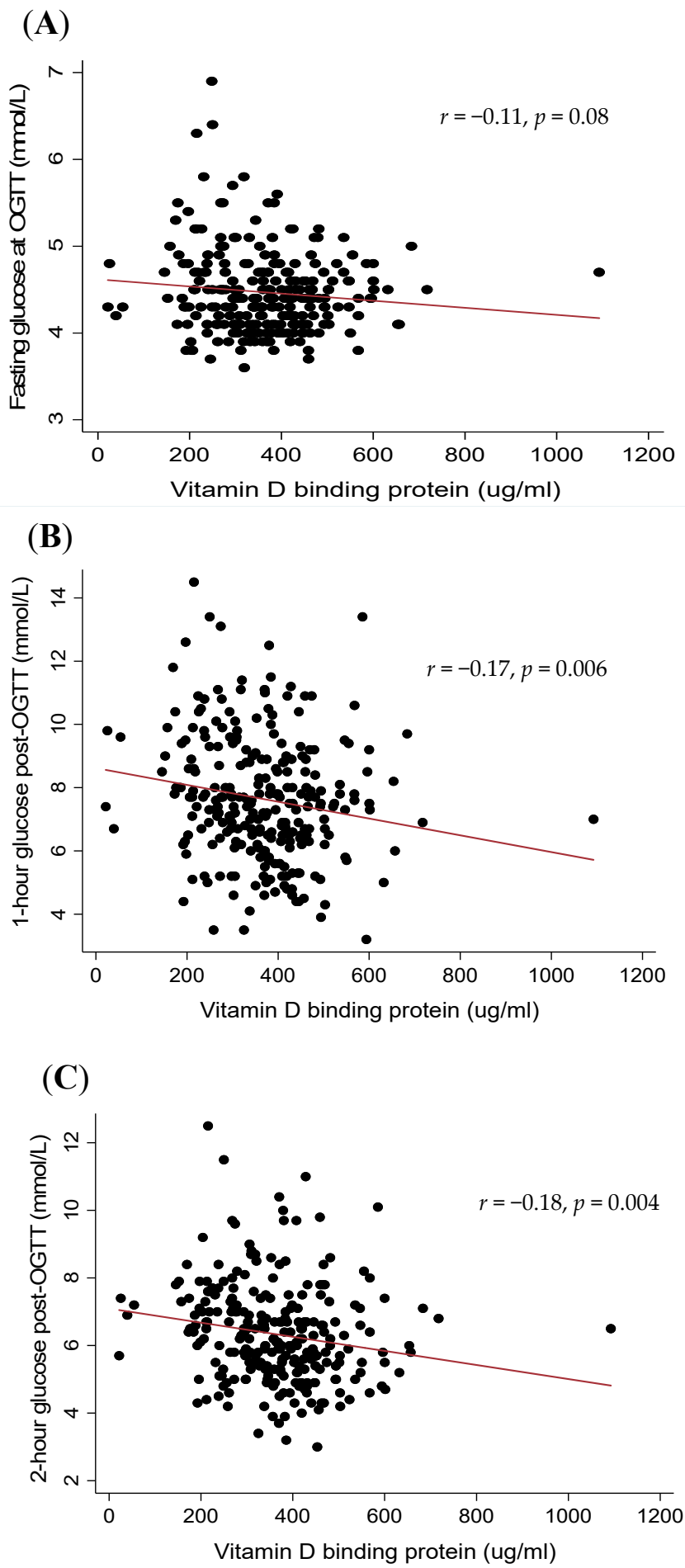

Figure 1. Scatterplots illustrating the correlations between vitamin D binding protein with fasting glucose (A); $1 \mathrm{~h}$ glucose (B); and $2 \mathrm{~h}$ glucose (C) post-oral glucose tolerance test (OGTT).

\subsection{Univariable Analyses of Vitamin D Metabolites and Pregnancy Outcomes}

The relationships between vitamin D metabolites and the pregnancy outcomes are presented in Table 5. VDBP was significantly associated with GDM (Table 5), whereby women who developed GDM had a significantly lower mean VDBP concentration in early pregnancy compared with the women who did not develop GDM $(325.4 \pm 109.1 \mu \mathrm{g} / \mathrm{mL}$ versus $371.3 \pm 127.7 \mu \mathrm{g} / \mathrm{mL}$ respectively, 
$p=0.01)$. VDBP was not correlated with pregnancy-induced hypertension, pre-eclampsia, placental abnormalities, pre-labour rupture of membranes (PROM) or preterm birth (all $p>0.05$; Table 5).

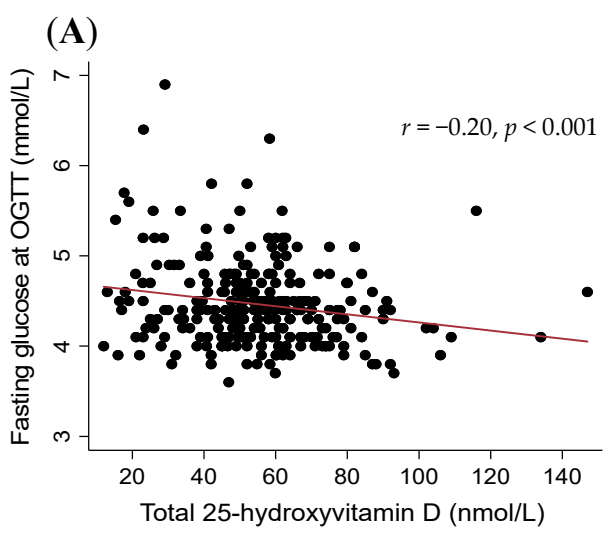

(B)

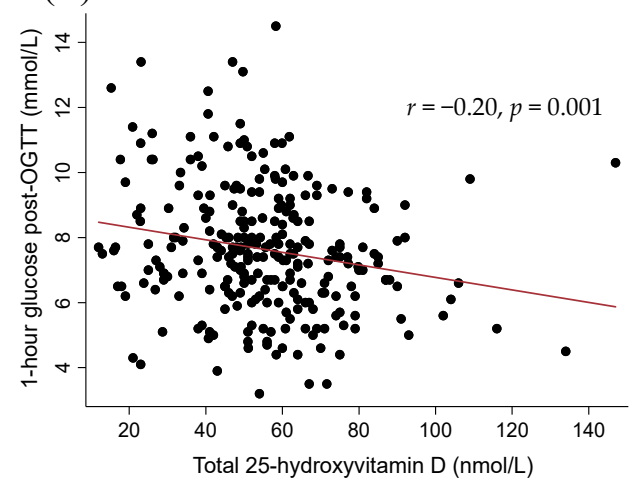

(C)

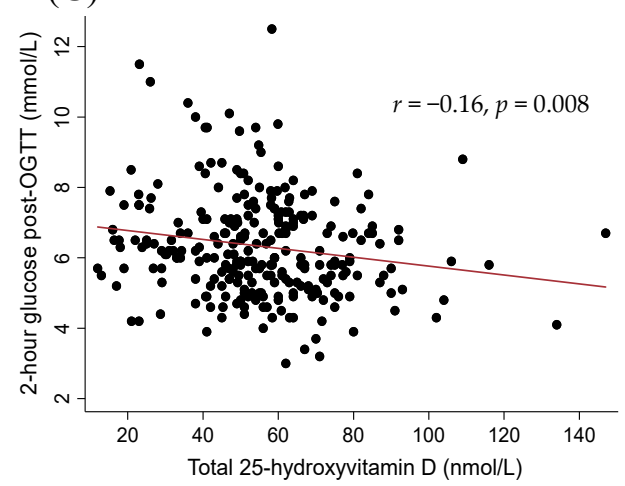

Figure 2. Scatterplots illustrating the correlations between total $25(\mathrm{OH}) \mathrm{D}$ with fasting glucose $(\mathbf{A}) ; 1 \mathrm{~h}$ glucose (B) and $2 \mathrm{~h}$ glucose (C) post-oral glucose tolerance test (OGTT).

Total 25(OH)D concentrations were also associated with GDM (Table 5), whereby women with GDM had a lower total 25(OH)D concentration compared with the women without GDM $(55.6 \pm 19.2$ versus $50.7 \pm 24.4 \mathrm{nmol} / \mathrm{L}$, respectively, $p=0.04)$. Higher total $25(\mathrm{OH}) \mathrm{D}$ concentrations in early pregnancy were also associated with a greater length of gestation $(\beta=0.02, p=0.002)$, but not with any of the other outcomes measured ( $p=0.06$ for pregnancy-induced hypertension; remaining outcomes $p \geq 0.1$; Table 5). Free and bioavailable 25(OH)D were not associated with any of the measured pregnancy outcomes (all $p>0.05$; Table 5). In an exploratory sub-analysis of the two cohorts separately, there were no associations between VDBP or any vitamin D metabolites with GDM or any pregnancy outcomes (all $p>0.05$ ) in the high-risk cohort (HLP, $n=91)$ or the low-risk cohort (CPO; $n=213$ ). 
Table 5. Univariable associations between vitamin D metabolites and maternal outcomes.

\begin{tabular}{|c|c|c|c|c|c|c|c|c|}
\hline \multirow{2}{*}{ Variable } & \multicolumn{2}{|l|}{ VDBP } & \multicolumn{2}{|c|}{ Total 25(OH)D } & \multicolumn{2}{|c|}{ Free $25(\mathrm{OH}) \mathrm{D}$} & \multicolumn{2}{|c|}{$\begin{array}{c}\text { Bioavailable } \\
\text { 25(OH)D }\end{array}$} \\
\hline & $\begin{array}{l}\beta \text { or OR } \\
(95 \% \mathrm{CI})\end{array}$ & $p$ & $\begin{array}{l}\beta \text { or OR } \\
(95 \% \mathrm{CI})\end{array}$ & $p^{*}$ & $\begin{array}{l}\beta \text { or OR } \\
(95 \% \mathrm{CI})\end{array}$ & $p^{*}$ & $\begin{array}{l}\beta \text { or OR } \\
(95 \% \mathrm{CI})\end{array}$ & $p^{*}$ \\
\hline GDM & $\begin{array}{c}0.98 \\
(0.97,0.99)\end{array}$ & 0.015 & $\begin{array}{c}0.98 \\
(0.97,0.99)\end{array}$ & 0.04 & $\begin{array}{c}0.99 \\
(0.93,1.06)\end{array}$ & 0.9 & $\begin{array}{c}1.01 \\
(0.92,1.10)\end{array}$ & 0.9 \\
\hline $\mathrm{PIH}$ & $\begin{array}{c}1 \\
(0.99,1.00)\end{array}$ & 0.5 & $\begin{array}{c}1.03 \\
(1.00,1.06)\end{array}$ & 0.06 & $\begin{array}{c}1.02 \\
(0.91,1.13)\end{array}$ & 0.3 & $\begin{array}{c}1.04 \\
(0.90,1.22)\end{array}$ & 0.3 \\
\hline Pre-eclampsia & $\begin{array}{c}0.99 \\
(0.99,1.00)\end{array}$ & 0.1 & $\begin{array}{c}1 \\
(0.97,1.03)\end{array}$ & 0.8 & $\begin{array}{c}1.06 \\
(0.98,1.14)\end{array}$ & 0.09 & $\begin{array}{c}1.12 \\
(0.99,1.24)\end{array}$ & 0.08 \\
\hline $\begin{array}{c}\text { Placental } \\
\text { abnormalities }\end{array}$ & $\begin{array}{c}1 \\
(0.99,1.00)\end{array}$ & 0.3 & $\begin{array}{c}0.99 \\
(0.98,1.01)\end{array}$ & 0.2 & $\begin{array}{c}0.94 \\
(0.87,1.02)\end{array}$ & 0.2 & $\begin{array}{c}0.94 \\
(0.85,1.03)\end{array}$ & 0.5 \\
\hline Gestation $^{+}$ & $\begin{array}{c}0.001^{\dagger} \\
(-0.001,-0.003)\end{array}$ & 0.5 & $\begin{array}{c}0.02^{\dagger} \\
(0.004,0.03)\end{array}$ & 0.002 & $\begin{array}{c}0.02^{\dagger} \\
(-0.03,0.07)\end{array}$ & 0.07 & $\begin{array}{c}0.05^{\dagger} \\
(-0.02,0.13)\end{array}$ & 0.07 \\
\hline Preterm birth & $\begin{array}{c}0.99 \\
(0.99,1.00)\end{array}$ & 0.3 & $\begin{array}{c}0.98 \\
(0.95,1.01)\end{array}$ & 0.1 & $\begin{array}{c}0.88 \\
(0.70,1.10)\end{array}$ & 0.4 & $\begin{array}{c}0.89 \\
(0.69,1.15)\end{array}$ & 0.6 \\
\hline PROM & $\begin{array}{c}1 \\
(0.99,1.00)\end{array}$ & 0.8 & $\begin{array}{c}0.99 \\
(0.98,1.01)\end{array}$ & 0.5 & $\begin{array}{c}0.94 \\
(0.84,1.06)\end{array}$ & 0.4 & $\begin{array}{c}0.94 \\
(0.81,1.08)\end{array}$ & 0.6 \\
\hline
\end{tabular}

Data were analysed using the general linear or simple logistic regression models for the continuous and binary outcomes, respectively, and the results are reported as beta coefficients ${ }^{\dagger}$ or odds ratios with $95 \%$ confidence intervals and the corresponding $p$-values; * $p$-values represent the significance of the analyses after vitamin D metabolite data were logarithmically transformed to the base 10 to approximate normality. Abbreviations: 25(OH)D, 25-hydroxyvitamin D; OR, odds ratio; VDBP, vitamin D binding protein; GDM, gestational diabetes mellitus; PIH, pregnancy-induced hypertension; PROM, premature rupture of membranes. Bold: denotes statistical significance at $p<0.05$.

\subsection{Multivariable Analyses of Vitamin D Metabolites and Pregnancy Outcomes}

Results of the multivariable logistic and linear regression analyses for the pregnancy outcomes are shown in Table 6. These models were adjusted for predetermined covariates based on clinical relevance to the pregnancy outcomes, including maternal age, BMI, and ethnicity. Additional variables including parity or previous history of GDM were adjusted for in further exploratory analyses.

Table 6. Multivariable regression analyses of the relationships between vitamin D metabolites and the pregnancy outcomes after adjustment for maternal covariates.

\begin{tabular}{|c|c|c|c|c|c|c|c|c|c|c|c|c|c|c|c|c|c|}
\hline \multirow{2}{*}{$\begin{array}{c}\text { Dependent } \\
\text { Variable }\end{array}$} & \multirow{2}{*}{ Model } & \multicolumn{4}{|c|}{ VDBP } & \multicolumn{4}{|c|}{ Total 25(OH)D } & \multicolumn{4}{|c|}{ Free $25(\mathrm{OH}) \mathrm{D}$} & \multicolumn{4}{|c|}{ Bioavailable 25(OH)D } \\
\hline & & $\beta$ & SE & $R^{2}$ & $p$ & $\beta$ & SE & $R^{2}$ & $p$ & $\beta$ & SE & $R^{2}$ & $p$ & $\beta$ & SE & $R^{2}$ & $p$ \\
\hline \multirow[b]{2}{*}{ GDM } & ge & -0.003 & 0.001 & 0.05 & 0.04 & -0.02 & 0.01 & 0.05 & 0.01 & -0.02 & 0.04 & 0.03 & 0.4 & -0.03 & 0.05 & 0.03 & 0.5 \\
\hline & + BMI & -0.003 & 0.001 & 0.06 & 0.05 & -0.01 & 0.01 & 0.05 & 0.04 & -0.01 & 0.04 & 0.04 & 0.7 & -0.01 & 0.05 & 0.04 & 0.7 \\
\hline \multirow{3}{*}{$\begin{array}{l}\text { Pregnancy-induced } \\
\text { hypertension }\end{array}$} & + age & 0.001 & 0.002 & 0.004 & 0.5 & 0.03 & 0.01 & 0.05 & 0.06 & 0.02 & 0.06 & 0.001 & 0.3 & 0.05 & 0.08 & 0.003 & 0.3 \\
\hline & $+\mathrm{BMI}$ & 0.001 & 0.003 & 0.002 & 0.7 & 0.02 & 0.02 & 0.01 & 0.2 & 0.001 & 0.07 & 0.0003 & 0.5 & 0.02 & 0.10 & 0.001 & 0.5 \\
\hline & + ethnicity & 0.001 & 0.003 & 0.05 & 0.7 & 0.01 & 0.02 & 0.05 & 0.5 & -0.02 & 0.09 & 0.05 & 0.8 & -0.01 & 0.11 & 0.05 & 0.9 \\
\hline Pre-eclampsia & + ethnicity & -0.003 & 0.003 & 0.09 & 0.4 & 0.007 & 0.02 & 0.08 & 0.9 & 0.07 & 0.04 & 0.11 & 0.1 & 0.10 & 0.06 & 0.11 & 0.1 \\
\hline \multirow{3}{*}{ Length of gestation } & + age & 0.0004 & 0.001 & 0.003 & 0.7 & 0.02 & 0.01 & 0.03 & 0.001 & 0.03 & 0.03 & 0.007 & 0.039 & 0.07 & 0.04 & 0.01 & 0.03 \\
\hline & + BMI & 0.0004 & 0.001 & 0.003 & 0.7 & 0.02 & 0.01 & 0.03 & 0.001 & 0.03 & 0.03 & 0.007 & 0.03 & 0.07 & 0.04 & 0.01 & 0.03 \\
\hline & + ethnicity & 0.0004 & 0.001 & 0.03 & 0.6 & 0.02 & 0.01 & 0.05 & 0.006 & 0.02 & 0.03 & 0.03 & 0.1 & 0.05 & 0.04 & 0.03 & 0.1 \\
\hline \multirow[b]{2}{*}{ Preterm birth } & + age & -0.002 & 0.002 & 0.01 & 0.3 & -0.02 & 0.01 & 0.02 & 0.1 & -0.14 & 0.12 & 0.02 & 0.4 & -0.13 & 0.13 & 0.01 & 0.6 \\
\hline & $+\mathrm{BMI}$ & -0.002 & 0.002 & 0.01 & 0.3 & -0.02 & 0.02 & 0.02 & 0.09 & -0.14 & 0.12 & 0.02 & 0.4 & -0.13 & 0.14 & 0.01 & 0.5 \\
\hline
\end{tabular}

Data are presented as unstandardized beta coefficients $(\beta)$ with the corresponding standard error $(\mathrm{SE})$, and $R^{2}$

(or pseudo $R^{2}$ for the logistic regression of binary outcomes). The plus signs indicate the addition of each variable to the model (e.g., for GDM, the first row is a model adjusted for age only, the second row is adjusted for age and BMI, and so on). Abbreviations: GDM, gestational diabetes mellitus; PROM, premature rupture of membranes. Bold: denotes statistical significance at $p<0.05$. 
VDBP remained significantly associated with GDM in the fully adjusted model with age, BMI and ethnicity as covariates $(\beta=-0.003, p=0.03)$, as well as after adjusting for parity, smoking status, or previous history of GDM in additional exploratory analyses $(\beta=-0.003, p=0.03$ in all the models). There were no associations between VDBP and other outcomes including pregnancy-induced hypertension, pre-eclampsia, PROM, preterm birth or the length of gestation in any of the multivariable models (Table 6).

A lower total 25(OH)D concentration remained associated with a higher risk of GDM after adjusting for age $(p=0.01)$ and BMI $(p=0.04)$, but this relationship was attenuated after adjusting for ethnicity ( $p=0.1$, Table 6$)$. A higher total $25(\mathrm{OH}) \mathrm{D}$ concentration remained associated with a greater length of gestation after adjustment for age $(p=0.001)$, BMI $(p=0.001)$ and ethnicity $(p=0.006$; Table 6$)$, but was not associated with any other outcomes (all $p>0.05$ ).

Higher free and bioavailable $25(\mathrm{OH}) \mathrm{D}$ concentrations were associated with a greater length of gestation in the models adjusted for age and BMI ( $p=0.03$ for all); however, these were attenuated upon adjustment for ethnicity (Table 6). Neither free 25(OH)D nor bioavailable 25(OH)D were associated with the other outcomes measured in any of the multivariable models (all $p>0.05$; Table 6).

\section{Discussion}

\subsection{Summary of Results}

To our knowledge, this is the first study to assess VDBP and total, free and bioavailable 25(OH)D concentrations in a well characterised multi-ethnic cohort of pregnant women. Moreover, although the association between total $25(\mathrm{OH}) \mathrm{D}$ and GDM has been extensively reported previously [25-27], this is the first study to report an association between VDBP and GDM. Our results show that women with lower concentrations of VDBP at early pregnancy had higher glucose levels at OGTT and a greater likelihood of developing GDM at 26-28 weeks gestation compared with women with higher VDBP concentrations, irrespective of free and bioavailable 25(OH)D concentrations. Lower total 25(OH)D concentrations in early pregnancy were also associated with higher glucose and a greater risk of GDM. These relationships remained significant after adjusting for age and BMI but only the relationship with VDBP persisted after the additional adjustment for ethnicity, demonstrating the robustness of the relationship between VDBP and GDM. We also show that higher total, free, and bioavailable $25(\mathrm{OH}) \mathrm{D}$ were associated with a greater length of gestation, but only the relationship with total $25(\mathrm{OH}) \mathrm{D}$ persisted in the fully-adjusted model.

\subsection{Comparison with Previous Literature and Potential Mechanisms}

In the present study, glucose concentrations post-OGTT and GDM were shown to be inversely associated with not just total 25(OH)D concentration, which has been widely reported [25,27-29] though inconsistently [30-32], but also with VDBP. This novel relationship between VDBP and GDM has not previously been reported with the single earlier study examining VDBP in women with and without GDM, finding no association [33], contrary to our findings. The lack of association reported by Xia et al. [33] may be attributed to their use of monoclonal assays to measure VDBP since, as acknowledged by the authors, these assays have been criticised for their lack of sensitivity to several genetically determined isoforms found in individuals who carry the GC- $1 F$ allele (predominantly in certain ethnicities) [17]. Conversely, our study utilised polyclonal assay technology, which is less affected by genetic and/or ethnic variations and this may explain the discrepant findings between the two studies. Based on our findings, it would be expected that low VDBP would correspond with higher free or bioavailable $25(\mathrm{OH}) \mathrm{D}$ concentrations, and that these metabolites would also be associated with a higher risk of GDM. This would be inconsistent with previous literature showing that free or bioavailable metabolites are associated with positive outcomes in several conditions [34,35], as well as the aforementioned studies and meta-analyses showing that higher total $25(\mathrm{OH}) \mathrm{D}$ is associated with a lower risk of GDM [25,27-29]. Indeed, higher total 25(OH)D in our study was associated with 
a reduced risk of GDM, consistent with previous literature, but while VDBP was correlated with free and bioavailable $25(\mathrm{OH}) \mathrm{D}$, we found no relationships between these metabolites and GDM. The absence of these latter associations may be due to our use of calculated free and bioavailable $25(\mathrm{OH}) \mathrm{D}$, rather that the direct measurement of these metabolites. It is also possible that changes in VDBP during pregnancy do not influence the bioavailability of vitamin $\mathrm{D}$, although evidence on this has been inconsistent. One study [36] reported lower bioavailable 25(OH)D in pregnant women compared to non-pregnant women, while another study [37] found no differences in free 25(OH)D between pregnant and non-pregnant women. In a study of 40 women across four timepoints in pregnancy [38], free $25(\mathrm{OH}) \mathrm{D}$ was reduced at all timepoints but there were no differences in total $25(\mathrm{OH}) \mathrm{D}$ compared with non-pregnant controls. Importantly, none of these studies assessed whether maternal free or bioavailable metabolites were associated with adverse pregnancy outcomes. A compensatory mechanism has been posited, whereby VDBP may exhibit a lower affinity for its metabolites during pregnancy to enable the level of free or bioavailable $25(\mathrm{OH}) \mathrm{D}$ to remain balanced, despite an increase in VDBP [39]. However, this altered affinity cannot be confirmed with the present data and requires further exploration.

There are several potential mechanisms underlying the association between VDBP and GDM. One explanation is that VDBP is the primary carrier protein and influences the proportions of the biologically active free and bioavailable $25(\mathrm{OH}) \mathrm{D}$ metabolites. This would mean that both higher VDBP and proportionally lower free and bioavailable 25(OH)D concentrations would be associated with GDM risk. As mentioned above, this was not demonstrated in our study or in other earlier studies $[33,40]$. We speculate that the influence of VDBP on GDM may be direct and independent of its role as a vitamin D carrier protein. For instance, VDBP may influence GDM directly via driving the actin scavenger system during inflammation and cell injury [41]. Recent evidence suggests that VDBP-actin complexes may serve as more than benign by-products of cell injury, potentially having an important role in both the mediation and resolution of inflammation and tissue injury [42]. Given that GDM and insulin resistance are underscored by inflammation [43,44], higher VDBP concentrations may mediate chronic low-grade inflammation, thereby influencing glucose metabolism and potentially reducing the risk of GDM. Another mechanism pertains to the interplay between VDBP, oestrogen and insulin. Both VDBP and insulin resistance are independently influenced by the rising oestrogen levels in pregnancy $[45,46]$. Studies show that VDBP increases exponentially, corresponding with the rise and peaks of oestrogen in pregnancy [45], alongside a documented decline in insulin sensitivity which is mediated by several factors including the increase in oestrogen [46]. Animal-based studies report that oestrogen counteracts the impact of insulin deficiency on vitamin D metabolism, and vice versa, supporting the likelihood of a complex relationship between VDBP and insulin resistant and deficient states such as GDM [47]. Sex hormones including oestrogen were not measured in the present study and the interplay between these hormones with VDBP and GDM warrants further exploration. VDBP may also be directly related to insulin regulation, as shown in a study of women with and without polycystic ovary syndrome, where VDBP levels were negatively correlated with serum insulin in both groups independent of the influence of sex hormones including oestrogen and androgen levels [48]. On the other hand, genetic studies have linked GC allelic variants of VDBP with serum glucose levels and the development of diabetes $[49,50]$. Although we did not explore genetic variants in the present study, the relationship between VDBP and GDM persisted after adjustment for ethnicity, suggesting that it may extend beyond ethnic or genetic differences.

We report that none of the vitamin D metabolites or VDBP were associated with placental disorders including pre-eclampsia or pregnancy-induced hypertension. Of the limited literature exploring VDBP in pregnancy, placental disorders, particularly pre-eclampsia, is an area which has been more extensively investigated. The role of VDBP in the actin-scavenger system of inflammation and tissue injury, independent of its involvement in the vitamin D metabolic system, has been consistently implicated in placental dysfunction [51,52]. VDBP displays a high binding affinity for free actin released as a result of cell death or tissue injury (which underlies the pathology of 
pre-eclampsia and other placental disorders [53]), and actively sequesters these products of tissue injury [54]. The increased expression of VDBP in pro-inflammatory states such as pregnancy or pre-eclampsia may be a mechanism by which actin debris is cleared. However, current findings lack consistency, with one study [51] reporting that VDBP is upregulated in women with early-onset pre-eclampsia and another reporting the decreased expression of VDBP in states of oxidative stress associated with the pathophysiology of pre-eclampsia [55]. These studies had a small number of pre-eclampsia cases (five and 11, respectively), as did the present study with only 10 cases, and hence were likely underpowered to identify true associations. Larger-scale studies to clarify the relationship between VDBP and placental disorders including preeclampsia are warranted.

The vitamin D metabolites analysed in this study, including VDBP, were not associated with preterm birth or PROM. Preterm birth and PROM have previously been linked to increased levels of VDBP in cervicovaginal fluid (CVF) [56], with a study by Liong et al. [57] finding that the VDBP/albumin CVF ratio was a more efficacious and precise biomarker than fetal fibronectin (fFN), the current gold standard, for predicting impending preterm labour. Overall, much of the existing research has explored VDBP levels in CVF, which may explain the discrepancies with our findings since VDBP in this study was measured in plasma/serum. The lack of significant findings for both PROM and preterm birth may also be due to insufficient statistical power, given the study sample size and the relatively small proportion of cases, particularly for preterm birth $(n=16 ; 5 \%)$. Nevertheless, the length of gestation was significantly associated with total $25(\mathrm{OH}) \mathrm{D}$ as well as with free and bioavailable $25(\mathrm{OH}) \mathrm{D}$, although the latter were attenuated after accounting for ethnicity in the multivariable models. The positive association between the length of gestation and total $25(\mathrm{OH}) \mathrm{D}$ has been reported previously [58-61], indicating that higher levels of total $25(\mathrm{OH}) \mathrm{D}$ may indeed be related to delivery at a later gestation. However, the relationships between free and bioavailable $25(\mathrm{OH}) \mathrm{D}$ with length of gestation await further study.

Mechanistically, vitamin D deficiency may promote proximal muscle weakness, thus having a possible role in reducing the length of gestation via the initiation of early labour [62]. Vitamin D also induces antimicrobial and anti-inflammatory properties, which may increase gestation by reducing the risk of infection and membrane rupture $[63,64]$. The relationships between vitamin D metabolites and the length of gestation are intriguing and with the plausibility of these mechanisms, warrant further exploration, particularly in larger cohorts with sufficient statistical power.

\subsection{Strengths and Limitations}

Some limitations should be acknowledged. The observational study design precludes assessments of causality and potential confounding cannot be ruled out. Because this was a secondary post-hoc analysis of two previous studies where recruitment and data collection were complete, no additional data or samples could be collected and there was no formal power calculation. As noted earlier, despite combining two cohorts, our sample size is modest and may have been underpowered to detect the associations between VDBP or total, free or bioavailable 25(OH)D metabolites with some of the pregnancy outcomes analysed. The single measurement of vitamin D metabolites during early pregnancy ( $<20$ weeks gestation) meant that we could not determine or adjust for temporal changes in vitamin D metabolites due to seasonality, sun exposure, supplement use or the dietary intake of vitamin D over the course of the pregnancy. The exact gestational week of data collection for each participant was not available, and including this in the statistical models may have influenced our results since both VDBP and BMI change over the course of pregnancy. We expect that the impact of this would be minimal, however, since data for this study were collected in early pregnancy, while it is known that VDBP and BMI change more drastically at the later stages of pregnancy. Nevertheless, our results should be interpreted in light of these important limitations. Only the maternal outcomes were examined and other birth or neonatal outcomes including those relevant to GDM such as neonatal birthweight or large-for-gestational-age should be assessed in future studies. Genetic differences and the potential contribution of vitamin $\mathrm{D}$ gene axis polymorphisms were not assessed in this 
study. We used Diasorin assays to measure the concentrations of total serum 25(OH)D rather than the gold-standard liquid chromatography mass-spectrometry method (LC/MS). Finally, free 25(OH)D was calculated rather than measured directly. Although the formula used in this study [23] has been shown to correlate well with direct measures of free 25(OH)D in most populations, some discrepancies have been identified, particularly in populations of African descent [65], of which there were three in this cohort. Further research utilising the newly developed and potentially superior ELISA for free $25(\mathrm{OH}) \mathrm{D}$ would be beneficial to corroborate our findings.

Notwithstanding these limitations, our study is the first to report a relationship between maternal VDBP and the development of GDM. The sample comprised a well characterized cohort of women at high and low risk of GDM, which allowed the examination of a diverse group where there was no confounding by comorbidities or medication use. This was also a multi-ethnic cohort, reflecting the cultural and linguistic diversity of the wider Australian population [66], which is important in VDBP studies, since earlier studies were conducted mostly in Caucasian cohorts, despite knowledge of the interplay between ethnicity, genetics and the vitamin D metabolic system [67]. Vitamin D metabolites and VDBP were measured earlier in pregnancy than most previous studies, which enabled the assessment of longitudinal relationships between these biomarkers and pregnancy outcomes. We also adjusted for potential confounding by age, BMI, and ethnicity as well as parity or previous history of GDM, all of which have seldom been considered in previous studies. We used polyclonal assays which are considered more reliable in measuring VDBP, particularly in ethnically diverse cohorts [17]. This is because polyclonal assays are less affected by VDBP genotype polymorphisms compared with the more widely used monoclonal assays, since the latter technique relies on recognising an epitope near the polymorphic region of VDBP, which has different affinities for the various VDBP haplotypes [17].

\section{Conclusions}

In summary, the present study provides a valuable contribution to the sparse literature on VDBP in pregnancy. As the prevalence of GDM continues to rise in line with increasing maternal obesity, further assessments of lifestyle factors including nutritional status have become paramount and can help inform clinical and public health actions in this area. Our findings suggest a novel association between maternal circulating VDBP concentrations in early pregnancy and GDM, and support previous reports of an association between total 25(OH)D and GDM, as well as the length of gestation. These findings are in agreement with genetic studies linking VDBP with GDM and add to this evidence by showing a relationship with circulating VDBP concentrations. Assessing circulating VDBP may offer a simpler and more cost-effective means for risk prediction and prevention on a population scale. However, to determine the potential utility of these metabolites in predicting and preventing conditions such as GDM, future studies should incorporate: large-scale and adequately powered sample sizes; a diverse representative cohort with ethnic and genetic assessments; frequent sampling to track metabolite concentrations using direct gold-standard measures (polyclonal, LC/MS, and ELISA assays for VDBP, total and free $25(\mathrm{OH}) \mathrm{D}$, respectively); and an assessment of lifestyle factors including sun exposure and vitamin D intake during pregnancy. Such studies can clarify the mechanistic pathways by which the vitamin D system interacts with the maternofetal axis and whether manipulation of these pathways can improve pregnancy outcomes.

Author Contributions: Conceptualization, A.M. and N.N.; methodology, A.M., S.J.E., and S.L.; formal analysis, M.F., C.M. and A.M.; investigation and data collection in original CPO and HLP studies, S.J.E., D.d.G., C.L.H., and H.J.T.; resources, A.M. and H.J.T.; writing-original draft preparation, M.F., and A.M.; writing-review and editing, M.F., S.J.E., D.d.G., C.M., S.L., C.L.H., H.J.T., N.N. and A.M.; supervision, A.M.; project administration, A.M.; funding acquisition, A.M. All authors have read and agreed to the published version of the manuscript.

Funding: As part of a larger study of biomarker analyses, funding for this work was provided by a secondment grant from the National Health and Medical Research Council (NHMRC) Centre for Research Excellence in Polycystic Ovarian Syndrome and a clinical exercise science seed grant from the Institute of Sport, Exercise 
and Active Living, Victoria University. AM, SJE and SL are funded by Biomedical fellowships provided by the NHMRC. HJT is a NHMRC Medical Research Future Fund Practitioner Fellow.

Acknowledgments: We would like to thank all volunteers who took part in the studies.

Conflicts of Interest: The authors declare no conflict of interest.

\section{References}

1. Mousa, A.; Naderpoor, N.; Teede, H.; Scragg, R.; De Courten, B. Vitamin D supplementation for improvement of chronic low-grade inflammation in patients with type 2 diabetes: A systematic review and meta-analysis of randomized controlled trials. Nutr. Rev. 2018, 76, 380-394. [CrossRef] [PubMed]

2. Mousa, A.; Abell, S.; Scragg, R.K.R.; De Courten, B. Vitamin D in Reproductive Health and Pregnancy. Semin. Reprod. Med. 2016, 34, e1-e13. [CrossRef]

3. Marquina, C.; Mousa, A.; Scragg, R.; De Courten, B. Vitamin D and cardiometabolic disorders: A review of current evidence, genetic determinants and pathomechanisms. Obes. Rev. 2018, 20, 262-277. [CrossRef] [PubMed]

4. Holick, M.F.; Chen, T. Vitamin D deficiency: A worldwide problem with health consequences. Am. J. Clin. Nutr. 2008, 87, 1080S-1086S. [CrossRef]

5. Ojo, O.; Weldon, S.M.; Thompson, T.; Vargo, E.J. The Effect of Vitamin D Supplementation on Glycaemic Control in Women with Gestational Diabetes Mellitus: A Systematic Review and Meta-Analysis of Randomised Controlled Trials. Int. J. Environ. Res. Public Health 2019, 16, 1716. [CrossRef] [PubMed]

6. Karras, S.N.; Koufakis, T.; Fakhoury, H.A.; Kotsa, K. Deconvoluting the Biological Roles of Vitamin D-Binding Protein During Pregnancy: A Both Clinical and Theoretical Challenge. Front. Endocrinol. 2018, 9, 259. [CrossRef] [PubMed]

7. Bikle, D.; Schwartz, J. Vitamin D Binding Protein, Total and Free Vitamin D Levels in Different Physiological and Pathophysiological Conditions. Front. Endocrinol. 2019, 10, 317. [CrossRef]

8. Bouillon, R.; Schuit, F.; Antonio, L.; Rastinejad, F. Vitamin D Binding Protein: A Historic Overview. Front. Endocrinol. 2020, 10, 910. [CrossRef]

9. Norman, A.W. $1 \propto, 25(\mathrm{OH}) 2$ Vitamin D3Vitamin D Nuclear Receptor (VDR) and Plasma Vitamin D-Binding Protein (DBP) Structures and Ligand Shape Preferences for Genomic and Rapid Biological Responses. In Principles of Bone Biology; Elsevier BV: Amsterdam, The Netherlands, 2008; pp. 749-778.

10. Fernando, M.; Ellery, S.J.; Marquina, C.; Lim, S.; Naderpoor, N.; Mousa, A. Vitamin D-Binding Protein in Pregnancy and Reproductive Health. Nutrients 2020, 12, 1489. [CrossRef]

11. Laopaiboon, M.; Lumbiganon, P.; Intarut, N.; Mori, R.; Ganchimeg, T.; Vogel, J.P.; Souza, J.P.; Gülmezoglu, A. Advanced maternal age and pregnancy outcomes: A multicountry assessment. BJOG Int. J. Obstet. Gynaecol. 2014, 121, 49-56. [CrossRef]

12. Mund, M.; Louwen, F.; Groneberg, D.A.; Gerber, A. Smoking and Pregnancy-A Review on the First Major Environmental Risk Factor of the Unborn. Int. J. Environ. Res. Public Health 2013, 10, 6485-6499. [CrossRef] [PubMed]

13. Verma, A.; Shrimali, L. Maternal Body Mass Index and Pregnancy Outcome. J. Clin. Diagn. Res. 2012, 6, 1531-1533. [CrossRef]

14. Newton, D.A.; Baatz, J.E.; Kindy, M.S.; Gattoni-Celli, S.; Shary, J.R.; Hollis, B.W.; Wagner, C.L. Vitamin D binding protein polymorphisms significantly impact vitamin D status in children. Pediatr. Res. 2019, 86, 662-669. [CrossRef] [PubMed]

15. Aloia, J.F.; Mikhail, M.; Dhaliwal, R.; Shieh, A.; Usera, G.; Stolberg, A.; Ragolia, L.; Islam, S. Free 25(OH)D and the Vitamin D Paradox in African Americans. J. Clin. Endocrinol. Metab. 2015, 100, 3356-3363. [CrossRef] [PubMed]

16. Daiger, S.P.; Miller, M.; Chakraborty, R. Heritability of quantitative variation at the group-specific component (Gc) locus. Am. J. Hum. Genet. 1984, 36, 663-676.

17. Nielson, C.M.; Jones, K.S.; Chun, R.F.; Jacobs, J.M.; Wang, Y.; Hewison, M.; Adams, J.S.; Swanson, C.M.; Lee, C.G.; Vanderschueren, D.; et al. Free 25-Hydroxyvitamin D: Impact of Vitamin D Binding Protein Assays on Racial-Genotypic Associations. J. Clin. Endocrinol. Metab. 2016, 101, 2226-2234. [CrossRef]

18. Harrison, C.L.; Lombard, C.; Strauss, B.J.; Teede, H.J. Optimizing healthy gestational weight gain in women at high risk of gestational diabetes: A randomized controlled trial. Obesity 2013, 21, 904-909. [CrossRef] 
19. Teede, H.J.; Harrison, C.L.; Teh, W.T.; Paul, E.; Allan, C.A. Gestational diabetes: Development of an early risk prediction tool to facilitate opportunities for prevention. Aust. N. Z. J. Obstet. Gynaecol. 2011, 51, 499-504. [CrossRef]

20. De Guingand, D.L.; Ellery, S.J.; Davies-Tuck, M.L.; Dickinson, H. Creatine and pregnancy outcomes, a prospective cohort study in low-risk pregnant women: Study protocol. BMJ Open 2019, 9, e026756. [CrossRef]

21. Hoffman, L.; Nolan, C.; Wilson, J.D.; Oats, J.J.N.; Simmons, D. Gestational diabetes mellitus-management guidelines. The Australasian Diabetes in Pregnancy Society. Med J. Aust. 1998, 169, 93-97. [CrossRef]

22. Walker, S.; Nassar, N.; Fung, A. Screening in Early Pregnancy for Adverse Perinatal Outcomes. The Royal Australian and New Zealand College of Obstetricians and Gynaecologists. Statement C-Obs 61, July 2015. Available online: https:/ranzcog.edu.au/RANZCOG_SITE/media/RANZCOG-MEDIA/Women\%27s\% 20Health/Statement\%20and\%20guidelines/Clinical-Obstetrics/Screening-in-Early-Pregnancy-for-AdversePerinatal-Outcomes-(C-Obs-61)-New-July-2015_1.pdf?ext=.pdf (accessed on 18 June 2020).

23. Bikle, D.; Bouillon, R.; Thadhani, R.; Schoenmakers, I. Vitamin D metabolites in captivity? Should we measure free or total 25(OH)D to assess vitamin D status? J. Steroid Biochem. Mol. Biol. 2017, 173, 105-116. [CrossRef]

24. Holick, M.F.; Binkley, N.; Bischoff-Ferrari, H.A.; Gordon, C.M.; Hanley, D.A.; Heaney, R.P.; Murad, M.H.; Weaver, C.M. Evaluation, Treatment, and Prevention of Vitamin D Deficiency: An Endocrine Society Clinical Practice Guideline. J. Clin. Endocrinol. Metab. 2011, 96, 1911-1930. [CrossRef] [PubMed]

25. Burris, H.H.; Rifas-Shiman, S.L.; Kleinman, K.; A Litonjua, A.; Huh, S.Y.; Rich-Edwards, J.W.; Camargo, C.A.; Gillman, M.W.; Rifas-Shiman, M.S.L. Vitamin D deficiency in pregnancy and gestational diabetes mellitus. Am. J. Obstet. Gynecol. 2012, 207, e1-e8. [CrossRef]

26. Zhang, Y.-B.; Gong, Y.; Xue, H.; Xiong, J.; Cheng, G. Vitamin D and gestational diabetes mellitus: A systematic review based on data free of Hawthorne effect. BJOG Int. J. Obstet. Gynaecol. 2018, 125, 784-793. [CrossRef] [PubMed]

27. Zhang, M.-X.; Pan, G.-T.; Guo, J.-F.; Li, B.-Y.; Qin, L.; Zhang, Z. Vitamin D Deficiency Increases the Risk of Gestational Diabetes Mellitus: A Meta-Analysis of Observational Studies. Nutrients 2015, 7, 8366-8375. [CrossRef]

28. Wei, S.Q.; Qi, H.-P.; Luo, Z.-C.; Fraser, W.D. Maternal vitamin D status and adverse pregnancy outcomes: A systematic review and meta-analysis. J. Matern. Neonatal Med. 2013, 26, 889-899. [CrossRef]

29. Palomer, X.; González-Clemente, J.M.; Blanco-Vaca, F.; Mauricio, D. Role of vitamin D in the pathogenesis of type 2 diabetes mellitus. Diabetes Obes. Metab. 2008, 10, 185-197. [CrossRef]

30. Farrant, H.J.; Krishnaveni, G.V.; Hill, J.C.; Boucher, B.J.; Fisher, D.J.; Noonan, K.; Osmond, C.; Veena, S.R.; Fall, C.H. Vitamin D insufficiency is common in Indian mothers but is not associated with gestational diabetes or variation in newborn size. Eur. J. Clin. Nutr. 2008, 63, 646-652. [CrossRef]

31. Makgoba, M.; Nelson, S.M.; Savvidou, M.D.; Messow, C.-M.; Nicolaides, K.; Sattar, N. First-Trimester Circulating 25-Hydroxyvitamin D Levels and Development of Gestational Diabetes Mellitus. Diabetes Care 2011, 34, 1091-1093. [CrossRef]

32. Park, S.; Yoon, H.-K.; Ryu, H.-M.; Han, Y.J.; Lee, S.W.; Park, B.K.; Park, S.-Y.; Yim, C.H.; Kim, S.-H. Maternal Vitamin D Deficiency in Early Pregnancy Is Not Associated with Gestational Diabetes Mellitus Development or Pregnancy Outcomes in Korean Pregnant Women in a Prospective Study. J. Nutr. Sci. Vitaminol. 2014, 60, 269-275. [CrossRef]

33. Xia, J.; Song, Y.; Rawal, S.; Wu, J.; Hinkle, S.N.; Tsai, M.Y.; Zhang, C. Vitamin D status during pregnancy and the risk of gestational diabetes mellitus: A longitudinal study in a multiracial cohort. Diabetes Obes. Metab. 2019, 21, 1895-1905. [CrossRef] [PubMed]

34. Sauer, C.G.; Loop, M.S.; Venkateswaran, S.; Tangpricha, V.; Ziegler, T.R.; Dhawan, A.; McCall, C.; Bonkowski, E.; Mack, D.R.; Boyle, B.; et al. Free and Bioavailable 25-Hydroxyvitamin D Concentrations are Associated With Disease Activity in Pediatric Patients With Newly Diagnosed Treatment Naïve Ulcerative Colitis. Inflamm. Bowel Dis. 2018, 24, 641-650. [CrossRef]

35. Ying, H.-Q.; Sun, H.-L.; He, B.-S.; Pan, Y.-Q.; Wang, F.; Deng, Q.-W.; Chen, J.; Liu, X.; Wang, S. Circulating vitamin $\mathrm{D}$ binding protein, total, free and bioavailable 25 -hydroxyvitamin $\mathrm{D}$ and risk of colorectal cancer. Sci. Rep. 2015, 5, 7956. [CrossRef] [PubMed] 
36. Kim, H.-J.; Ji, M.; Song, J.; Moon, H.-W.; Hur, M.; Yun, Y.-M. Clinical Utility of Measurement of Vitamin D-Binding Protein and Calculation of Bioavailable Vitamin D in Assessment of Vitamin D Status. Ann. Lab. Med. 2017, 37, 34-38. [CrossRef] [PubMed]

37. Schwartz, J.B.; Lai, J.; Lizaola, B.; Kane, L.; Weyland, P.; Terrault, N.A.; Stotland, N.; Bikle, D. Variability in free 25(OH) vitamin D levels in clinical populations. J. Steroid Biochem. Mol. Biol. 2013, 144, 156-158. [CrossRef] [PubMed]

38. Bouillon, R.; Van Assche, F.A.; Van Baelen, H.; Heyns, W.; De Moor, P. Influence of the Vitamin D-binding Protein on the Serum Concentration of 1,25-Dihydroxyvitamin D3. J. Clin. Investig. 1981, 67, 589-596. [CrossRef]

39. Bikle, D.D.; Gee, E.; Halloran, B.; Haddad, J.G. Free 1,25-dihydroxyvitamin D levels in serum from normal subjects, pregnant subjects, and subjects with liver disease. J. Clin. Investig. 1984, 74, 1966-1971. [CrossRef]

40. Gustafsson, M.K.; Romundstad, P.R.; Stafne, S.N.; Helvik, A.-S.; Stunes, A.K.; Mørkved, S.; Salvesen, K. Åsmund; Thorsby, P.M.; Syversen, U. Alterations in the vitamin D endocrine system during pregnancy: A longitudinal study of 855 healthy Norwegian women. PLoS ONE 2018, 13, e0195041. [CrossRef]

41. Delanghe, J.R.; Speeckaert, R.; Speeckaert, M.M. Behind the scenes of vitamin D binding protein: More than vitamin D binding. Best Pr. Res. Clin. Endocrinol. Metab. 2015, 29, 773-786. [CrossRef]

42. Kew, R.R. The Vitamin D Binding Protein and Inflammatory Injury: A Mediator or Sentinel of Tissue Damage? Front. Endocrinol. 2019, 10, 470. [CrossRef]

43. Radaelli, T.; Varastehpour, A.; Catalano, P.; Mouzon, S.H.-D. Gestational diabetes induces placental genes for chronic stress and inflammatory pathways. Diabetes 2003, 52, 2951-2958. [CrossRef] [PubMed]

44. Pantham, P.; Aye, I.L.; Powell, T.L. Inflammation in maternal obesity and gestational diabetes mellitus. Placenta 2015, 36, 709-715. [CrossRef] [PubMed]

45. Zhang, J.Y.; Lucey, A.; Horgan, R.; Kenny, L.C.; Kiely, M.E. Impact of pregnancy on vitamin D status: A longitudinal study. Br. J. Nutr. 2014, 112, 1081-1087. [CrossRef] [PubMed]

46. Sonagra, A.D.; Biradar, S.M.; K., D.; D.S., J.M. Normal Pregnancy-A State of Insulin Resistance. J. Clin. Diagn. Res. 2014, 8, CC01-CC03. [CrossRef] [PubMed]

47. Nyomba, B.L.; Bouillon, R.; De Moor, P. Evidence for an interaction of insulin and sex steroids in the regulation of vitamin D metabolism in the rat. J. Endocrinol. 1987, 115, 295-301. [CrossRef]

48. Kuliczkowska-Plaksej, J.; Pasquali, R.; Milewicz, A.; Lwow, F.; Jedrzejuk, D.; Bolanowski, M. Serum Vitamin D Binding Protein Level Associated with Metabolic Cardiovascular Risk Factors in Women with the Polycystic Ovary Syndrome. Horm. Metab. Res. 2018, 51, 54-61. [CrossRef]

49. Shi, A.; Wen, J.; Liu, G.; Liu, H.; Fu, Z.; Zhou, J.; Zhu, Y.; Liu, Y.; Guo, X.; Xu, J. Genetic variants in vitamin D signaling pathways and risk of gestational diabetes mellitus. Oncotarget 2016, 7, 67788-67795. [CrossRef] [PubMed]

50. Wang, Y.; Wang, O.; Li, W.; Ma, L.; Ping, F.; Chen, L.; Nie, M. Variants in Vitamin D Binding Protein Gene Are Associated With Gestational Diabetes Mellitus. Medicine 2015, 94, e1693. [CrossRef] [PubMed]

51. Kolialexi, A.; Tsangaris, G.T.; Sifakis, S.; Gourgiotis, D.; Katsafadou, A.; Lykoudi, A.; Marmarinos, A.; Mavreli, D.; Pergialiotis, V.; Fexi, D.; et al. Plasma biomarkers for the identification of women at risk for early-onset preeclampsia. Expert Rev. Proteom. 2017, 14, 269-276. [CrossRef]

52. Tannetta, D.; Redman, C.W.; Sargent, I.L. Investigation of the actin scavenging system in pre-eclampsia. Eur. J. Obstet. Gynecol. Reprod. Biol. 2013, 172, 32-35. [CrossRef]

53. Bailey, L.J.; Alahari, S.; Tagliaferro, A.; Post, M.; Caniggia, I. Augmented trophoblast cell death in preeclampsia can proceed via ceramide-mediated necroptosis. Cell Death Dis. 2017, 8, e2590. [CrossRef]

54. Harper, K.D.; McLeod, J.F.; A Kowalski, M.; Haddad, J.G. Vitamin D binding protein sequesters monomeric actin in the circulation of the rat. J. Clin. Investig. 1987, 79, 1365-1370. [CrossRef] [PubMed]

55. Ma, R.; Gu, Y.; Zhao, S.; Sun, J.; Groome, L.J.; Wang, Y. Expressions of vitamin D metabolic components VDBP, CYP2R1, CYP27B1, CYP24A1, and VDR in placentas from normal and preeclamptic pregnancies. Am. J. Physiol. Metab. 2012, 303, E928-E935. [CrossRef] [PubMed]

56. Kook, S.Y.; Park, K.H.; Jang, J.A.; Kim, Y.M.; Park, H.; Jeon, S.J. Vitamin D-binding protein in cervicovaginal fluid as a non-invasive predictor of intra-amniotic infection and impending preterm delivery in women with preterm labor or preterm premature rupture of membranes. PLoS ONE 2018, 13, e0198842. [CrossRef] [PubMed] 
57. Liong, S.; Di Quinzio, M.; Fleming, G.; Permezel, M.; Rice, G.; Georgiou, H.M. New biomarkers for the prediction of spontaneous preterm labour in symptomatic pregnant women: A comparison with fetal fibronectin. BJOG Int. J. Obstet. Gynaecol. 2014, 122, 370-379. [CrossRef]

58. Wang, Y.; Li, H.; Zheng, M.; Wu, Y.; Zeng, T.; Fu, J.; Zeng, D. Maternal vitamin D deficiency increases the risk of adverse neonatal outcomes in the Chinese population: A prospective cohort study. PLoS ONE 2018, 13, e0195700. [CrossRef]

59. Khalessi, N.; Kalani, M.; Araghi, M.; Farahani, Z. The Relationship between Maternal Vitamin D Deficiency and Low Birth Weight Neonates. J. Fam. Reprod. Health 2015, 9, 113-117.

60. Chen, Y.; Zhu, B.; Wu, X.; Li, S.; Tao, F. Association between maternal vitamin D deficiency and small for gestational age: Evidence from a meta-analysis of prospective cohort studies. BMJ Open 2017, 7, e016404. [CrossRef]

61. Francis, E.; Hinkle, S.N.; Song, Y.; Rawal, S.; Donnelly, S.R.; Zhu, Y.; Chen, L.; Zhang, C. Longitudinal Maternal Vitamin D Status during Pregnancy Is Associated with Neonatal Anthropometric Measures. Nutrients 2018, 10, 1631. [CrossRef]

62. Merewood, A.; Mehta, S.D.; Chen, T.; Bauchner, H.; Holick, M.F. Association Between Vitamin D Deficiency and Primary Cesarean Section. Obstet. Gynecol. Surv. 2009, 64, 501-502. [CrossRef]

63. Liu, N.; Hewison, M. Vitamin D, the placenta and pregnancy. Arch. Biochem. Biophys. 2012, 523, 37-47. [CrossRef] [PubMed]

64. Qin, L.-L.; Lu, F.-G.; Yang, S.-H.; Xu, H.-L.; Luo, B.-A. Does Maternal Vitamin D Deficiency Increase the Risk of Preterm Birth: A Meta-Analysis of Observational Studies. Nutrients 2016, 8, 301. [CrossRef] [PubMed]

65. Schwartz, J.B.; Lai, J.; Lizaola, B.; Kane, L.; Marková, S.; Weyland, P.; Terrault, N.A.; Stotland, N.; Bikle, D. A comparison of measured and calculated free $25(\mathrm{OH})$ vitamin D levels in clinical populations. J. Clin. Endocrinol. Metab. 2014, 99, 1631-1637. [CrossRef] [PubMed]

66. Australian Bureau of Statistics. 2071.0-Census of Population and Housing: Reflecting AustraliaStories from the Census, 2016. Cultural Diversity in Australia, 2016. 2017. Available online: https://www.abs.gov.au/ausstats/abs@.nsf/Lookup/by\%20Subject/2071.0 2016 Main\%20Features Cultural\%20Diversity\%20Data\%20Summary 30 (accessed on 18 June 2020).

67. Christensen, M.H.; Scragg, R.K.R. Consistent ethnic specific differences in diabetes risk and vitamin D status in the National Health and Nutrition Examination Surveys. J. Steroid Biochem. Mol. Biol. 2016, 164, 4-10. [CrossRef] [PubMed]

(C) 2020 by the authors. Licensee MDPI, Basel, Switzerland. This article is an open access article distributed under the terms and conditions of the Creative Commons Attribution (CC BY) license (http://creativecommons.org/licenses/by/4.0/). 